\title{
Frações da matéria orgânica em agregados em áreas de terra preta arqueológica, Pará, Brasil
}

A maior parte dos solos amazônicos apresentam baixa fertilidade, porém são observadas manchas descontínuas onde ser verificam maiores quantidades de nutrientes e teores de carbono orgânico total (COT) elevados, sendo essas áreas denominadas de terra preta arqueológicas (TPA's). A matéria orgânica do solo (MOS) é um dos índices mais utilizados para avaliar a qualidade do solo, a qual pode ser quantificada pelo COT presente nas substâncias húmicas (SH) e no carbono determinado através do fracionamento granulométrico, sendo uma maior proteção do COT bem como das frações da MOS observada nos agregados. Neste sentido, o objetivo desse estudo foi avaliar o conteúdo de COT das SHs e determinado através do fracionamento granulométrico da MOS em áreas de TPA's com diferentes usos do solo. As amostras de foram coletadas no município de Santarém, Pará, em áreas com diferentes formas de manejo e condições edáficas, a saber: (P1) cultivo de milho e mandioca com intensa utilização agrícola e sem aplicação de fertilizantes; (P2) cultivo de mandioca, apresentando histórico de cultivos agrícolas em sucessão por mais de dez anos; (P3) área de floresta secundaria, localizada próxima ao rio tapajós; (P4 e P5) áreas em pousio por mais de seis anos com presenças de forrageiras e (P6) com cultivo de feijão-caupi. As amostras foram coletadas nas profundidades de 0,00-0,05; 0,05-0,10 e 0,10-0,20 m. Nos agregados foram determinados os teores de (COT), carbono orgânico das SHs (ácidos fúlvicos - C-FAF, ácidos húmicos - C-FH e humina - C-FHUM) e realizado o fracionamento físico granulométrico da MOS (fração particulada - COp e fração associada aos minerais - COam). Os diferentes usos do solo não comprometeram os teores de carbono orgânico associado as frações da matéria orgânica dos agregados de TPA, sendo observado nas áreas alto grau de similaridade, e a área P1 apresentando valores de MOS superiores às demais áreas.

\section{Fractions of organic matter in aggregates in archaeological black earth areas, Pará, Brazil}

\begin{abstract}
Most of the Amazonian soils have low fertility, however discontinuous patches are observed where there are higher amounts of nutrients and high levels of total organic carbon (TOC), these areas being called archaeological black earth (TPA's). Soil organic matter (MOS) is one of the most used indices to assess soil quality, which can be quantified by the COT present in humic substances $(\mathrm{SH})$ and in the carbon determined through granulometric fractionation, being a greater protection of the COT as well as the MOS fractions observed in the aggregates. In this sense, the objective of this study was to evaluate the TOC content of the SHs and determined through the MOS granulometric fractionation in TPA's areas with different land uses. The samples were collected in the municipality of Santarem, Pará, in areas with different management methods and edaphic conditions, namely: (P1) cultivation of corn and cassava with intense agricultural use and without application of fertilizers; (P2) cassava cultivation, with a history of agricultural crops in succession for more than ten years; (P3) secondary forest area, located near the Tapajós River; (P4 and P5) fallow areas for more than six years with forages and (P6) with cowpea cultivation. Samples were collected at depths of 0.00-0.05; 0.05-0.10 and 0.10-0.20 m. In the aggregates, the contents of (COT), organic carbon of the SHs (fulvic acids - C-FAF, humic acids - C-FH and humine - C-FHUM) were determined and the physical particle size fractionation of the MOS (particulate fraction - COp and fraction associated with minerals - COam). The different uses of the soil did not compromise the levels of organic carbon associated with the fractions of organic matter of the TPA aggregates, being observed in the areas a high degree of similarity, and the area P1 presenting MOS values higher than the other areas.
\end{abstract}

Keywords: Quality of organic matter; Anthropic soils; Black Indian soil.

Topic: Ciências do Solo

Reviewed anonymously in the process of blind peer.
Received: 02/12/2020

Approved: 22/12/2020
Mateus Alves de Sousa (iD

Universidade Federal do Oeste do Pará, Brasil http://lattes.cnpq.br/7484606325846483 http://orcid.org/0000-0002-9696-743X mateussica@gmail.com

Iolanda Maria Soares Reis (D)

Universidade Federal do Oeste do Pará, Brasil http://lattes.cnpq.br/9591454475619777 http://orcid.org/0000-0001-6619-0730 iolandareis@outlook.com

Adão Pires de Almada (ic Universidade Federal do Oeste do Pará, Brasil http://lattes.cnpq.br/2225653352583779 http://orcid.org/0000-0002-0578-3150 adaoalmada1000@hotmail.com
Celeste Queiroz Rossi (iD)

Universidade Federal do Oeste do Pará, Brasil http://lattes.cnpq.br/4242217997345355 http://orcid.org/0000-0002-9068-4834 celesteqrossi@yahoo.com.br

\section{Marcos Gervasio Pereira (iD)}

Universidade Federal Rural do Rio de Janeiro, Brasil http://lattes.cnpq.br/3657759682534978 http://orcid.org/0000-0002-1402-3612 mgervasiopereira01@gmail.com

Luiz Alberto Rodrigues da Silva Pinto Universidade Federal Rural do Rio de Janeiro, Brasil http://lattes.cnpq.br/5006918904667368

http://orcid.org/0000-0002-4369-4511 I arodrigues@yahoo.com.br
Cristiane Figueira da Silva (iD

Universidade Federal Rural do Rio de Janeiro, Brasil http://lattes.cnpq.br/5734423515627169 http://orcid.org/0000-0003-4606-3149 cfigueirasilva@yahoo.com.br

Otavio Augusto Queiroz dos Santos (iD) Universidade Federal Rural do Rio de Janeiro, Brasil http://lattes.cnpq.br/5893308385515780 http://orcid.org/0000-0001-9554-303X otavioqueiroz7@hotmail.com G.; PINTO, L. A. S. R.; SILVA, C. F.; SANTOS, O. A. Q.. Frações da matéria orgânica em agregados em áreas de terra preta arqueológica, Pará, Brasil. Revista Ibero Americana de Ciências Ambientais, v.11, n.7, p.16-23, 2020. DOI: http://doi.org/10.6008/CBPC21796858.2020 .007 .0002 


\section{INTRODUÇÃO}

No Bioma Amazônico verifica-se de maneira geral, solos com baixa fertilidade, devido ao seu alto grau de intemperismo, mas é comum serem observadas machas de solos descontínuas com coloração escura que apresentam fragmentos de cerâmica, boa fertilidade natural e teores de carbono elevados, sendo popularmente conhecidas como terra preta de índio (TPI) ou terra preta arqueológicas (TPA) (GLASER et al., 2012). A formação desses solos remete ao período pré-colombiano quando a Bacia Amazônica estava densamente ocupada e assim possibilitando condições favoráveis paras as modificações antrópicas que ainda são encontradas na região (MACEDO et al., 2019).

Nos ecossistemas naturais, o conteúdo de matéria orgânica do solo (MOS) se encontra em equilíbrio com equivalência nos fluxos de entrada e saída, mas quando ocorrem estresses provocados por ações antrópicas esse equilíbrio é comprometido, ocasionando reduções nos teores e fluxo de entrada de MOS no sistema (SILVA NETO et al., 2012). Esse padrão não é observado nas TPA's, devido à persistência da MOS que está relacionada com a presença de carbono pirogênico, estabilização de agregados e interações com argilominerais (GLASER, 1999; GLASER et al., 2003). Sendo que este carbono vegetal é altamente resistente as altas temperaturas e umidade. Sua formação origina-se a partir de queimadas com menores temperaturas e longa duração, num processo que favorece a retenção de nutrientes como P, Ca, N, S (ANTOINETTE et al., 2010).

Avaliações dos teores de carbono orgânico total (COT) do solo, nas frações granulométricas e húmicas da MOS são de grande relevância para uma maior compreensão dos efeitos do manejo sobre a estrutura do solo e demais características edáficas (LOSS et al., 2014). Os agregados são as unidades básicas da estrutura do solo, os quais são constituídos por partículas unitárias e compostos minerais e orgânicos atuando como agentes cimentantes (TISDALL et al., 1982; ZHANG et al., 2014; FONTE et al., 2012).

A partir do exposto, verifica-se que as práticas de manejo do solo podem exercer influência sobre os atributos químicos e físicos do solo provocando mudanças na estrutura e comunidade microbiana do solo (BIREESCU et al., 2014). Nesse sentido, o objetivo desse estudo foi avaliar o conteúdo de COT das SHs e determinado através do fracionamento granulométrico da MOS em áreas de TPA's com diferentes usos do solo

\section{MATERIAIS E MÉTODOS}

A área de estudo está localizada entre a confluência de dois grandes rios, Amazonas e Tapajós, município de Santarém, Pará. O clima da região segundo classificação de Koppen é do tipo Am, equatorial úmido, com estação seca bem definida e um período com altas precipitações, apresenta temperatura média anual variando de 25 a 28 C, com umidade relativa do ar média de $86 \%$ e precipitação média anual de 1920 mm (SOUSA et al., 2018).

As amostras de TPA's foram coletadas em seis áreas que apresentavam diferentes formas de manejo e condições edáficas. Na área (P1) cultiva-se milho e mandioca com intensa utilização agrícola e sem 
aplicação de fertilizantes; (P2) Nessa área era realizado o cultivo de mandioca, apresentando histórico de cultivos agrícolas em sucessão por mais de dez anos.; (P3) Área de floresta secundária, localizada próxima ao rio Tapajós.; (P4 e P5) Áreas em pousio por mais de seis anos com presenças de forrageiras e (P6) Área com cultivo de feijão-caupi (SOUSA et al., 2020).

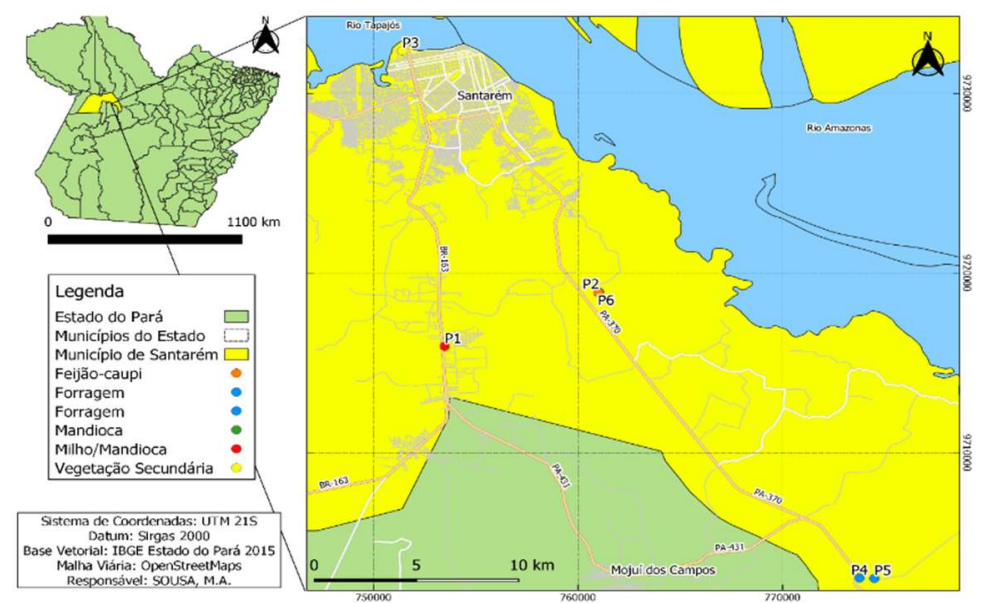

Figura 1: Localização do município e pontos de coleta de solos de terra preta arqueológica. Fonte: Sousa et al. (2020).

Para coleta de agregados do solo foram retiradas amostras indeformadas (torrões) nas profundidades de 0,00-0,05; 0,05-0,10 e 0,10-0,20 m. As amostras foram secas ao ar e peneiradas com o emprego de tamises de 8,0 e 4,0 mm de diâmetro de malha (TEIXEIRA et al., 2017). Os agregados retidos nesse intervalo, foram destorroados e passados por peneira de 2,0 $\mathrm{mm}$ de malha, obtendo-se assim a fração terra fina seca ao ar (TFSA), e posteriormente determinados:

Carbono orgânico total (COT) - determinado via oxidação úmida da matéria orgânica com dicromato de potássio em meio ácido (YEOMANS et al., 1988).

Fracionamento químico para obtenção de substâncias húmicas (SH) - foram obtidas pela extração e separação por meio da solubilidade diferencial da matéria orgânica em meio básico ou ácido (ácidos fúlvicos e húmicos) e o resíduo (humina) (BENITES et al., 2003). A determinação do carbono orgânico em cada uma das frações húmicas, ácidos fúlvicos (C-FAF), ácidos húmicos (C-FAH) e humina (C-FHUM), também foi realizada de acordo com Yeomans et al. (1988).

Fracionamento físico granulométrico - Foi utilizado o método proposto por Cambardella et al. (1992), que consiste na separação da MOS em duas frações, fração particulada (relacionada à fração areia do solo) e fração associada aos minerais (relativa às frações argila e silte). A quantificação do carbono orgânico da fração particulada (COP) da MOS também foi realizada segundo Yeomans et al. (1988) e o carbono orgânico da fração associada aos minerais (COAM) da MOS foi quantificado pela diferença entre o COT e o COP.

Os dados obtidos foram padronização a média zero e variância unitária, em seguida submetido a estatística multivariada, análise de agrupamentos (AA), por método hierárquico, utilizando a distância euclidiana como coeficiente de semelhança e o método Ward, como algoritmo de ligação de grupo, também foi realizado análise de componente principal (ACP), para discriminar as amostras de TPA em gráficos 
bidimensionais (Biplot), construído por autovetores (componentes principais) que são gerados da matriz de covariância, a partir das variáveis originais (HAIR et al., 2005). As análises foram processadas pelo software estatístico Statistica, versão 12.0 .

\section{RESULTADOS E DISCUSSÃO}

\section{COT e frações da MOS em agregados}

Os resultados de COT associados as frações da MOS nos agregados de solos de TPA são apresentados na Tabela 1. Os teores de COT variaram de 53,02 a 23,98 $\mathrm{g} \mathrm{kg}^{-1}$, sendo na área P1 observado os maiores valores em todas as profundidades. Segundo Glaser et al. (2000) os teores de carbono em TPA's representam até 35\% da MOS, estes teores diferem de solos não antrópicos, os quais apresentam no máximo 14\%.

Em estudo de agregados de solos em sistema plantio direto (SPD) e SPD + integração lavoura pecuária floresta (ILPF), Loss et al. (2011) observaram que os maiores valores de COT nos respectivos manejos foram de 30,30 e 36,92 $\mathrm{g} \mathrm{kg}^{-1}$, sendo esses valores próximos aos observados em áreas de TPAs. Contudo, nos solos de TPA deste estudo foram quantificados teores de COT superiores a estes valores, nas profundidades de 0,00-0,05 e 0,05-0,10 m. Já na profundidade de 0,10-0,20 m, os valores quantificados foram inferiores, sendo exceção observada na área P1. Esse padrão indica a alta resistência do carbono das TPAs, mesmo as áreas que recebem manejos agronômicos mínimos apresentam teores de COT mais elevados quando comparadas com sistemas de manejos mais tecnificados.

Tabela 1: Carbono orgânico total e frações físicas e húmicas da MOS de agregados em áreas de TPA's, submetidas à diferentes coberturas vegetais e manejo, no município de Santarém-PA.

\begin{tabular}{|c|c|c|c|c|c|c|}
\hline \multirow[t]{2}{*}{ Áreas } & $\begin{array}{l}\text { COT } \\
\mathrm{g} \mathrm{kg}^{-1}\end{array}$ & COp & COam & C-FHUM & C-FAF & $\mathrm{C}-\mathrm{FAH}$ \\
\hline & $\begin{array}{l}\mathrm{g} \mathrm{kg}^{-1} \\
0,00-0,05 \mathrm{~m}\end{array}$ & & & & & \\
\hline P1 & 52,77 & 7,49 & 45,28 & 13,20 & 1,67 & 5,03 \\
\hline P2 & 37,43 & 23,71 & 13,72 & 6,18 & 1,25 & 4,52 \\
\hline P3 & 39,21 & 9,03 & 30,18 & 8,01 & 3,22 & 4,28 \\
\hline P4 & 42,89 & 9,04 & 33,85 & 7,30 & 2,25 & 9,64 \\
\hline P5 & 48,66 & 14,99 & 33,67 & 9,97 & 2,57 & 5,46 \\
\hline \multirow[t]{2}{*}{ P6 } & 33,14 & 3,84 & 29,30 & 1,97 & 1,51 & 2,58 \\
\hline & \multicolumn{6}{|c|}{$0,05-0,10 \mathrm{~m}$} \\
\hline P1 & 53,05 & 4,39 & 48,66 & 16,58 & 1,80 & 4,97 \\
\hline P2 & 32,65 & 5,53 & 27,12 & 1,83 & 0,83 & 5,16 \\
\hline P3 & 40,39 & 8,97 & 31,42 & 6,18 & 2,83 & 7,88 \\
\hline P4 & 38,79 & 4,42 & 34,37 & 9,41 & 2,02 & 5,81 \\
\hline P5 & 30,80 & 5,03 & 25,77 & 3,65 & 1,18 & 4,29 \\
\hline \multirow[t]{2}{*}{ P6 } & 41,42 & 5,42 & 35,99 & 7,30 & 0,28 & 2,28 \\
\hline & \multicolumn{6}{|c|}{$0,10-0,20 \mathrm{~m}$} \\
\hline P1 & 44,54 & 3,28 & 41,27 & 12,22 & 1,38 & 4,61 \\
\hline P2 & 28,39 & 3,07 & 25,32 & 2,25 & 0,28 & 5,91 \\
\hline P3 & 24,68 & 4,21 & 20,46 & 3,37 & 1,28 & 3,42 \\
\hline P4 & 23,98 & 3,04 & 20,95 & 4,78 & 1,12 & 3,42 \\
\hline P5 & 25,91 & 3,28 & 22,63 & 3,79 & 0,66 & 3,35 \\
\hline P6 & 34,48 & 3,33 & 31,15 & 3,37 & 0,89 & 7,62 \\
\hline
\end{tabular}

Cultivo de milho e mandioca, trata-se de área com intensa utilização agrícola, sem uso de nenhum tipo de fertilizante (P1); cultivo de mandioca, área cultivada por mais de dez anos com culturas agrícolas em sistema de sucessão, sem uso de fertilizante (P2); floresta secundaria, área de preservação, localizada próxima ao rio Tapajós (P3); forrageiras em pousio por mais de seis anos (P4 e P5); e cultivo de feijão-caupi (P6). Carbono orgânico total (COT); carbono orgânico particulado (COp); carbono orgânico associado aos minerais (COam); carbono orgânico da fração ácido fúlvico (C-FAF); carbono orgânico da fração ácido húmico (C-FAH); e carbono orgânico da fração humina (C-FHUM). 
Segundo Brossi et al. (2014), foram observados em diferentes localidades e uso do solo que as TPA's sob vegetação secundária apresentaram maiores teores de COT, em agregados, corroborando em parte com os resultados observados neste estudo, onde na área P3 foram observados valores semelhantes, e por vezes superiores, as demais áreas, sendo exceção a área P1 em que se verificaram maiores teores de COT.

Quanto ao fracionamento físico da MOS dos agregados, os maiores teores de COp foram verificados na área P2 na profundidade de 0,00-0,05 m (23,71 $\left.\mathrm{g} \mathrm{kg}^{-1}\right)$, para área $\mathrm{P3}$, nas profundidades 0,05-0,10 e 0,100,20 m (8,96 e 4,21 $\left.\mathrm{g} \mathrm{kg}^{-1}\right)$, respectivamente. Para os dados de COam foi observado na área P1 maiores valores para todas as profundidades. Segundo Golchin et al. (1994), o COp é uma fração constituída de resíduos de vegetais e contribuindo para maior proteção física aos agregados.

Avaliando as frações físicas da MOS em diferentes formas de uso do solo (lavoura, pastagem nativa e sistema silvipastoril), Loss et al. (2014), observaram os maiores teores de COam de aproximadamente 10,1 $\mathrm{g} \mathrm{kg}^{-1}$, enquanto nas áreas de TPA's em todas profundidades foram quantificados valores mais elevados.

Avaliando os valores da SH dos agregados de TPA, em comparação aos teores de C-FAH, C-FHUM e C-FAF observa-se em todas as áreas a predominância de frações mais estáveis, C-FHUM e C-FAH, em especial na área P1, na qual foram verificados maiores valores em todas as profundidades (Tabela 1), variando de $16,57 \mathrm{~g} \mathrm{~kg}^{-1}$ a 12,22 $\mathrm{g} \mathrm{kg}^{-1}$. Para a fração mais solúvel (C-FAF), foram observados os menores teores com decréscimo em profundidade para todas as áreas. Estes resultados corroboram os estudos realizados por de Lima et al. (2002), Cunha et al. (2007), Cunha et al. (2009) e Sousa et al. (2020), apesar desses estudos não terem sido realizados com agregados, foi observado o mesmo padrão constatado neste estudo.

\section{Análise exploratória multivariada (AA e ACP)}

Através da análise AA verificou-se para a profundidade de 0,00-0,05 m (Figura 2A) a formação de dois grupos, quando considerado uma distância euclidiana próxima a 4, sendo que um grupo foi formado pelas áreas P6 e P2, as quais se distinguiram das demais áreas estudadas.
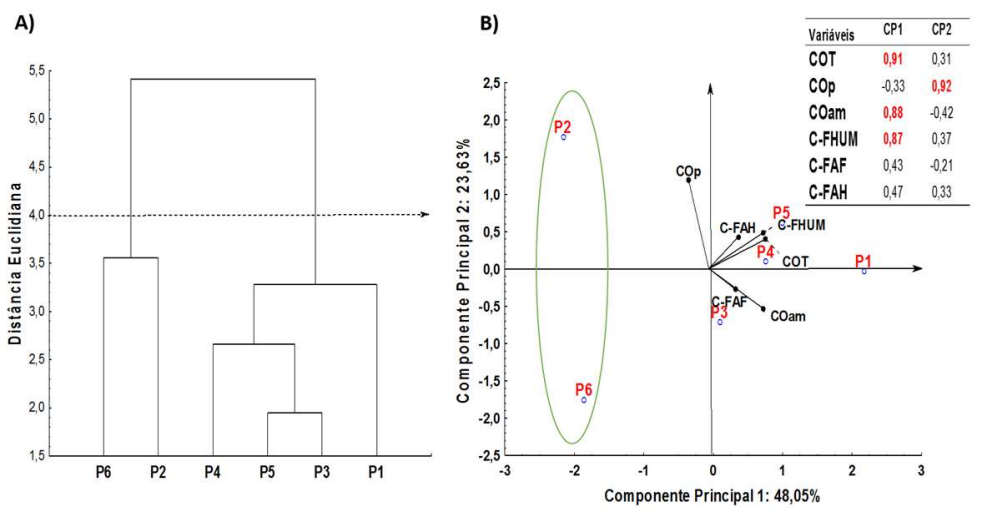

Figura 2: Análise de agrupamento (AA) e de componentes principais (ACP) (B) de agregados de TPA na camada de 0,00-0,05 m, em função do carbono orgânico total e frações húmicas e físicas da MOS. Cultivo de milho e mandioca, trata-se de área com intensa utilização agrícola, sem uso de nenhum tipo de fertilizante (P1); cultivo de mandioca, área cultivada por mais de dez anos com culturas agrícolas em sistema de sucessão, sem uso de fertilizante (P2); floresta secundaria, área de preservação, localizada próxima ao rio Tapajós (P3); forrageiras em pousio por mais de seis anos (P4 e P5); e cultivo de feijão-caupi (P6). Carbono orgânico total (COT); carbono orgânico particulado (COp); carbono orgânico associado aos minerais (COam); carbono orgânico da fração ácido fúlvico (C-FAF); carbono orgânico da fração ácido húmico (C-FAH); e carbono orgânico da fração humina (C-FHUM). 
A ACP apresentada no gráfico Biplot explicou 71,68\% da variabilidade total dos dados, sendo o CP1 responsável por 48,05\% e o CP2 23,63\% (Figura 2B), é observado uma forte correlação positiva entre o CP1 e as variáveis COT, COam e C-FHUM, sendo estes importantes para discriminar as áreas P6 e P2, as quais apresentaram menores teores destas variáveis, enquanto que o grupo formado pelas demais áreas apresentaram teores mais elevados das referidas variáveis. Já no CP2, a variável COp apresentou correlação forte e positiva, complementando a análise. De acordo com Bayer et al. (2004), os agregados do solo fornecem maior proteção física das frações que compõem MOS.

Para a profundidade de 0,05-0,10 m (Figura 3A) a AA apontou a formação de dois grandes grupos, considerando uma distância euclidiana próxima a 5, sendo que para as áreas P1 e P3 observou-se maior distância de discriminação em comparação as demais. Na ACP foi observada explicação de 91,01\% pelos CPs 1 e 2, a área P1 apresentou alta associação aos teores de COT, COam e C-HUM apresentando 51,18\% da variabilidade explicada pelo CP1. Já na área P3 observou-se padrão o inverso, associando-se com COp, C-FAF e C-FAH no CP2.
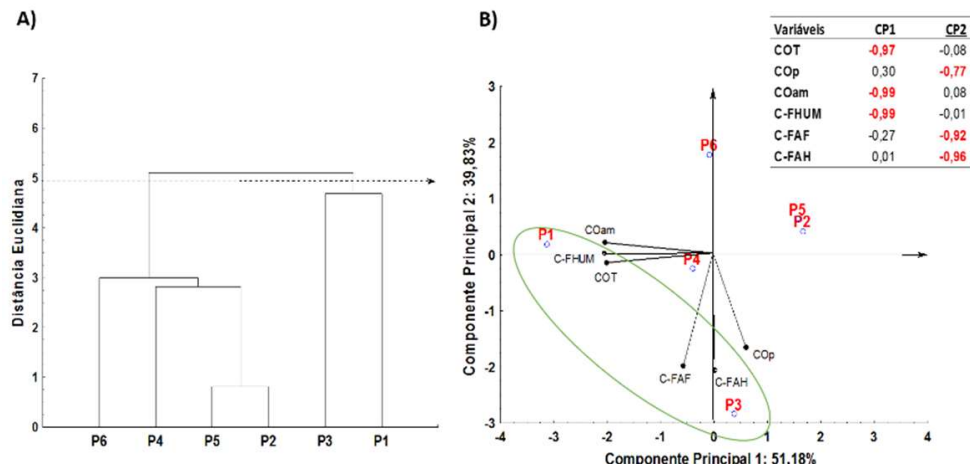

Figura 3: Análise de agrupamento (AA) e de componentes principais (ACP) (B) de agregados de TPA na camada de 0,05-0,10 m, em função do carbono orgânico total e frações húmicas e físicas da MOS. Cultivo de milho e mandioca, trata-se de área com intensa utilização agrícola, sem uso de nenhum tipo de fertilizante (P1); cultivo de mandioca, área cultivada por mais de dez anos com culturas agrícolas em sistema de sucessão, sem uso de fertilizante (P2); floresta secundaria, área de preservação, localizada próxima ao rio Tapajós (P3); forrageiras em pousio por mais de seis anos (P4 e P5); e cultivo de feijão-caupi (P6). Carbono orgânico total (COT); carbono orgânico particulado (COp); carbono orgânico associado aos minerais (COam); carbono orgânico da fração ácido fúlvico (C-FAF); carbono orgânico da fração ácido húmico (C-FAH); e carbono orgânico da fração humina (C-FHUM).

De acordo com Novotny et al. (2009), os ácidos húmicos das TPAs são ricos em estruturas aromáticas condensadas e com grupos carboxílicos ligados diretamente a estas estruturas, garantindo alta estabilidade térmica e estrutural. Neste sentido, nos agregados da área P1 quantificaram-se os maiores teores de ácidos húmicos possibilitando uma maior estabilidade dos mesmos.

Na camada de 0,10-0,20 m (Figura 4A) na AA quando considerada uma distância euclidiana próxima a 5,5, observa-se a formação de dois grupos, sendo a área mais distante a P1 e as demais áreas agrupadas entre si. Através da análise da ACP (Figura 4B), verifica-se uma variabilidade total de $82,30 \%$, sendo 51,22\% na CP1 e 31,08\% na CP2, na CP1 foi observada maior correlação das variáveis COT, COam, C-HUM, demonstrando a importância dessas em discriminar a variabilidade da área P1, as variáveis COp, C-FAF e C$\mathrm{FAH}$, se destacaram no CP2, sendo determinante para explicar a variabilidade da área P6. 

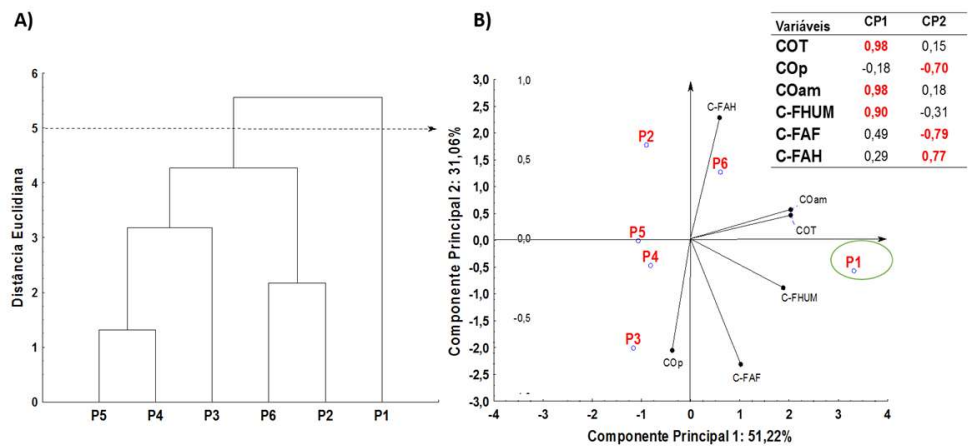

Figura 4: Análise de agrupamento (AA) e de componentes principais (ACP) (B) de agregados de TPA na camada de 0,10-0,20 m, em função do carbono orgânico total e frações húmicas e físicas da MOS. Cultivo de milho e mandioca, trata-se de área com intensa utilização agrícola, sem uso de nenhum tipo de fertilizante (P1); cultivo de mandioca, área cultivada por mais de dez anos com culturas agrícolas em sistema de sucessão, sem uso de fertilizante (P2); floresta secundaria, área de preservação, localizada próxima ao rio Tapajós (P3); forrageiras em pousio por mais de seis anos (P4 e P5); e cultivo de feijão-caupi (P6). Carbono orgânico total (COT); carbono orgânico particulado (COp); carbono orgânico associado aos minerais (COam); carbono orgânico da fração ácido fúlvico (C-FAF); carbono orgânico da fração ácido húmico (C-FAH); e carbono orgânico da fração humina (C-FHUM).

Em trabalho realizado por Sousa et al. (2020) nas mesmas áreas desse estudo foi observado que a área $\mathrm{P} 3$ foi segregada das demais áreas, quando através da técnica de $A A$, sendo que os autores consideraram os atributos de fertilidade e as frações químicas da MOS, para essa avaliação. Enquanto neste trabalho, a área P3 apresentou similaridade com as demais áreas, além de terem sido verificados elevados teores de carbono nas frações, indicando que os agregados dessa área apresentam grande potencial de preservação das frações da MOS.

\section{CONCLUSÕES}

Os diferentes usos do solo não comprometeram os teores de carbono orgânico associado as frações da matéria orgânica dos agregados de TPA, sendo observado nas áreas alto grau de similaridade. Na área P1 foi observada maiores teores de MOS em comparação às demais.

\section{REFERÊNCIAS}

ANTOINETTE, M. G. A. W.; STEPHEN, P. A.. Locating Amazonian Dark Earths: creating an interactive GIS of known locations. Journal of Latin American Geography, v.9, 2010.

BAYER, C.; MARTIN NETO, L.; MIELNICZUK, J.; PAVINATO, A.. Armazenamento de carbono em frações lábeis da matéria orgânica de um Latossolo Vermelho sob plantio direto. Pesquisa Agropecuária Brasileira, Brasília, v.9, n.7, 2004. DOI: https://doi.org/10.1590/S0100-204X2004000700009

BENITES, V. M.; MADARI, B.; MACHADO, P. L. O. A.. Extração e fracionamento quantitativo de substâncias húmicas do solo: um procedimento simplificado de baixo custo. Rio de Janeiro: Embrapa Solos, 2003.

BIREESCU, L.; BIREESCU, G.; SELLITTO, M. V.. Assessing the soil physiological potential using pedo-biological diagnosis under minimum-tillage system and mineral fertilization. Environmental Quality, v.13, p.01-07, 2014.

BROSSI, M. J. L.; MENDES, L. W.; GERMANO, M. G.; LIMA, A. B.; TSAI, S. M.. Assessment of Bacterial bph Gene in
Amazonian Dark Earth and Their Adjacent Soils. Plos One, v.9, n.6, 2014. DOI:

https://doi.org/10.1371/journal.pone.0099597

CAMBARDELLA, C. A.; ELLIOTT, E. T.. Methods for physical separation and characterization of soil organic matter fractions. Geoderma, Amsterdam, v.56, p.449-457, 1993. DOI: https://doi.org/10.1016/0016-7061(93)90126-6

CUNHA, T. J. F.; MADARI, B. E.; BENITES, V. M.; CANELLAS, L. P.; NOVOTNY, E. H.; MOUTTA, R. O.; TROMPOWSKY, P. M.; SANTOS, G. A.. Fracionamento químico da matéria orgânica e características de ácidos húmicos de solos com horizonte a antrópico da Amazônia (Terra Preta). Acta Amazônica, Manaus, v.37, n.1, 2007. DOI: https://doi.org/10.1590/\$0044-59672007000100010

CUNHA, T. J. F.; MADARI, B. E.; CANELLAS, L. P.; RIBEIRO, L. P.; BENITES, V. M.; SANTOS, G. A.. Soil organic matter and fertility of anthropogenic dark earths (Terra Preta de Índio) in the Brazilian Amazon basin. Revista Brasileira de Ciência do Solo, Viçosa, v.33 n.1, 2009. DOI: 
https://doi.org/10.1590/S0100-06832009000100009

FONTE, S. J.; QUINTERO, D. C.; VELASQUEZ, E.; LAVELLE, P.. Interactive effects of plants and earthworms on the physical stabilization of soil organic matter in aggregates. Plant Soil, v.359, p.205-214, 2012. DOI:

https://doi.org/10.1007/s11104-012-1199-2

GLASER, B.. Eigenschaften und Stabilität des Humuskörpers der Indianer schwarzerden Amazoniens. Bayreuther Bodenkundliche Berichte. 1999.

GLASER, B.; BALASHOV, E.; HAUMAIER, L.; GUGGENBERGER, G.; ZECH, W.. Black carbon in density fractions of anthropogenic soils of the Brazilian Amazon region. Organic Geochem., v.31, p.669-678, 2000. DOI: https://doi.org/10.1016/S0146-6380(00)00044-9

GLASER, B.; BIRK, J. J.. State of the scientific knowledge on properties and genesis of Anthropogenic Dark Earths in Central Amazonia (terra preta de I'ndio). Geochimica et Cosmochimica Acta, v.82, p.39-51, 2012. DOI: https://doi.org/10.1016/j.gca.2010.11.029

GLASER, B.; GUGGENBERGER, G.; ZECH, W.; LOURDES-RUIVO M.. Estabilidade da matéria orgânica do solo na Amazônia Terra Escura. Dentro Terra escura da Amazônia: origem, propriedades e gerenciamento (ed. J. Lehmann et al.). Kluwer Academic Publishers, Dodrecht, p.141-158, 2003.

GOLCHIN, A.; OADES, J. M.; SKJEMSTAD, J. O.; CLARKE, P.. Soil structure and carbon cycling. Australian Journal Soil Reserach, v.32, n.5, p.1043-1068, 1994. DOI: https://doi.org/10.1071/SR9941043

HAIR, J. J. F.; ANDERSON, R. E.; TATHAM, R. L.; BLACK, W. C.. Análise multivariada de dados. 5 ed. Porto Alegre: Bookman, 2005.

LIMA, H. N.; SCHAEFER, C. E. R.; MELLO, J. W. V.; GILKES, R. J.; KER, J. C.. Pedogenesis and pre-Colombian land use of ${ }^{\prime}$ 'Terra Preta Anthrosols' ('Indian black earth') of Western Amazonia. Geoderma, v.110, p.1-17, 2002. DOI: https://doi.org/10.1016/S0016-7061(02)00141-6

LOSS, A.; PEREIRA, M. G.; GIACOMO, S. G.; PERIN, A.; ANJOS, L. H. C.. Agregação, carbono e nitrogênio em agregados do solo sob plantio direto com integração lavoura-pecuária. Pesquisa Agropecuaria Brasileira, Brasília, v.46, n.10, p.1269-1276, 2011. DOI: https://doi.org/10.1590/S0100204X2011001000022

LOSS, A.; RIBEIRO, E. C.; PEREIRA, M. G.; COSTA, E. M.. Atributos físicos e químicos do solo em sistemas de consórcio e sucessão de lavoura, pastagem e silvipastoril em Santa Teresa, ES. Bioscience Journal, Uberlândia, v.30, n.5, p.1347-1357, 2014.
MACEDO, R. S.; TEIXEIRA, W. G.; LIMA, H. N.; SOUZA, A. C. G.; SILVA, F. W. R.; ENCINAS, O. C.; NEVES, E. G.. Amazonian dark earths in the fertile floodplains of the Amazon River, Brazil: an example of non-intentional formation of anthropic soils in the Central Amazon region. Boletim do Museu Paraense Emílio Goeldi. Ciências Humanas, Belém, v.14, n.1, p.207-227, 2019. DOI: https://doi.org/10.1590/1981$\underline{81222019000100013}$

NOVOTNY, E. H.; HAYES, M. H. B.; MADARI, B. E.; BONAGAMBA, T. J.; AZEVEDO, E. R.; SOUZA, A. A.; SONG, G.; NOGUEIRA, C. M.; MANGRICH, A. S.. Lessons from the Terra Preta de Índios of the Amazon region for the utilisation of charcoal for soil amendment. Journal of the Brazilian Chemical Society, São Paulo, v.20, n.6, p.1003-1010, 2009. DOI: https://doi.org/10.1590/S0103-50532009000600002

SILVA NETO, S. P.; SANTOS, A. C.; LEITE, R. L. L.; DIM, V. P.; NEVES NETO, D. N.; SILVA, J. E. C.. Variação espacial do teor de matéria orgânica do solo e produção de gramínea em pastagens de Capim-marandu. Bioscience Journal Uberlândia, v.28, p.41-53, 2012.

SOUSA, M. A.; REIS, I. M. S.; ALMADA, A. P.; ROSSI, C. Q.; PEREIRA, M. G.; PINTO, L. A. R. S.; SILVA, C. F.; SANTOS, O. A $Q$.. Atributos químicos e frações da matéria orgânica em solos antrópicos na Amazônia Oriental. Brazilian Journal of Development, Curitiba, v.6, n.5, p.29623-29643, 2020.

SOUSA, W. N.; BRITO, N. F.; BARROS, I. B.; SOUSA, J. T. R.; SIA, E. F.; REIS, I. M. S.. Resposta do feijão-caupi à inoculação de Bradyrhizobium japonicum, adubação nitrogenada e nitrogênio do solo. Revista Agroecossistemas, v.10, n.2, p.298-308, 2018. DOI: http://dx.doi.org/10.18542/ragros.v10i2.5167

TEIXEIRA, P. C.; DONAGEMMA G. K.; WENCESLAU, A. F.; TEIXEIRA, G.. Manual de métodos de análise de solo. 3 ed. Rio de Janeiro: Embrapa Solos, 2017.

TISDALL, J. M.; OADES, J. M.. Organic matter and waterstable aggregates in soils. Journal Soil Science, v.33, p.141163, 1982. DOI: https://doi.org/10.1111/j.13652389.1982.tb01755.x

YEOMANS, J. C.; BREMNER, J. M.. A rapid and precise method for routine determination of organic carbon in soil. Commun. Soil Science Society of America. Anal., v.19, p.1467-1476, 1988. DOI: http://dx.doi.org/10.1080/00103628809368027

ZHANG, P.; WEI, T.; JIA, Z.; HAN, Q.; REN, X.; LI, Y.. Effects of Straw Incorporation on Soil Organic Matter and Soil WaterStable Aggregates Content in Semiarid Regions of Northwest China. Plos One, v.9, 2014. DOI: https://doi.org/10.1371/journal.pone.0092839

A CBPC - Companhia Brasileira de Produção Científica (CNPJ: 11.221.422/0001-03) detém os direitos materiais desta publicação. Os direitos referem-se à publicação do trabalho em qualquer parte do mundo, incluindo os direitos às renovações, expansões e disseminações da contribuição, bem como outros direitos subsidiários. Todos os trabalhos publicados eletronicamente poderão posteriormente ser publicados em coletâneas impressas sob coordenação da Sustenere Publishing, da Companhia Brasileira de Produção Científica e seus parceiros autorizados. Os (as) autores (as) preservam os direitos autorais, mas não têm permissão para a publicação da contribuição em outro meio, impresso ou digital, em português ou em tradução. 